Teresa Eminowicz-Jaśkowska Uniwersytet Jagielloński, Kraków jaskowas@neostrada.pl

\title{
Juan Ruiz, Arcipreste de Hita: Libro de Buen Amor, la obra maestra del Medioevo español ${ }^{1}$
}

\begin{abstract}
:
Libro de Buen Amor by Juan Ruiz: a Masterpiece of Spanish Middle Ages

The article presents the Libro de Buen Amor in its universal dimension within its cultural and psychological connotations, being at the same time an introduction to the medieval Spanish poetry.

Keywords: Spanish medieval poetry, Libro de Buen Amor, Arcipreste de Hita
\end{abstract}

${ }^{1}$ Traducción de Marta Pawłowska. El artículo en la versión original polaca (Juan Ruiz Arcipreste de Hita: "Księga o Dobrej Miłości» - arcydzieło hiszpańskiego Średniowiecza) se publicó en Studia Iberystyczne, U. DąmbskaProkop, T. Eminowicz (eds.), Viridis, Kraków 1994, p. 7-18. 


\section{Streszczenie:}

Libro de Buen Amor Juana Ruiza - arcydzieło hiszpańskiego średniowiecza

Artykuł przedstawia Księgę o Dobrej Miłości w jej wymiarze uniwersalnym, a także ukazuje kulturowe i psychologiczne konotacje dzieła, będąc zarazem wprowadzeniem do średniowiecznej poezji hiszpańskiej.

Slowa kluczowe: średniowieczna poezja hiszpańska, Libro de Buen Amor, Arcipreste de Hita.

Acerca de la poesía medieval española no se ha escrito mucho en polaco. Tampoco hay traducciones que nos permitan conocer todos los géneros de la poesía en lengua castellana. Disponemos sólo de la traducción del Cantar de Mío Cid y de algunas antologías, muy reducidas, que comprenden una selección de romances, algunos poemas líricos y fragmentos de poemas más largos. Todo ello no refleja la riqueza de la poesía de la Península Ibérica que se cultivó en la Edad Media y que está recogida en los Cancioneros del siglo XV. Estas colecciones nos presentan el proceso de la creación de la poesía castellana, la variedad de sus formas y contenidos y el perfeccionamiento de los recursos estilísticos. Un lector que no conozca dicha lengua, tampoco encontrará información acerca de la versificación española. La falta de acceso tanto a la literatura dedicada a este tema como a la poesía original, incluso traducida, imposibilita el conocimiento de esta hermosa y rica creación literaria. Quizá este esbozo rellene este hueco, aunque sea en un grado mínimo.

Como iniciación a la poesía medieval española, dedicaremos este artículo al Libro de Buen Amor de Juan Ruiz, Arcipreste de Hita: la obra maestra del siglo XIV que es una síntesis de todo lo anterior a su aparición y además indica nuevas tendencias de la literatura española.

A modo de introducción, vale la pena dedicarle algunas palabras al autor, puesto que su vida refleja la suerte de los habitantes de la Península Ibérica de la época de la Reconquista. Hasta hace poco, no se sabía mucho sobre su vida, excepto lo que él mismo quiso contarnos en las páginas de su libro. Ya el hecho de que la obra no fuera anóni- 
ma es una prueba de su modernidad y asimismo nos da la posibilidad de buscar huellas del autor en los archivos. El Congreso Internacional organizado con ocasión del 700 aniversario de la muerte del rey Alfonso X el Sabio (1984) dio pie a investigaciones que esclarecieron una serie de hechos hasta entonces desconocidos. Entre otros se investigó el enigma de dónde provenía Juan Ruiz, lo cual nos permitió comprender algunos aspectos de su obra.

En 1280, el hijo del rey Alfonso X el Sabio dirigió una expedición militar cristiana cuyo objetivo era conquistar Alcalá de Benzayde (actualmente Alcalá la Real) en Andalucía. Por el camino se toparon con tropas árabes, las cuales derrotaron sus huestes en Moclín. Muchos caballeros de renombre fallecieron en esa batalla y algunos de ellos terminaron cautivos. Entre los muertos, se hallaron Rodríguez González, el Maestre de la Orden de Santiago y uno de sus hijos, Juan Ruiz. El otro hijo, Arias González, se encontró en el cautiverio y pasó quince años en el reino granadino de los nazaríes. El Maestre Rodríguez González era abuelo de nuestro escritor y Arias González su padre, según las investigaciones de Carmen Llovera llevadas a cabo en los archivos de Alcalá la Real y presentadas en el antedicho Congreso.

Durante los quince años de cautiverio Arias González tuvo seis hijos de una esclava cristiana. No era un caso aislado. Los cristianos en el cautiverio árabe a veces tenían hijos. No se sabe nada sobre las hijas nacidas allí; sin embargo, los hijos muy a menudo volvían a los reinos cristianos. La épica española nos ha dejado testimonios de ello. El poema Los siete infantes de Lara menciona a un chico nacido en el cautiverio, llamado Mudarra, que jura vengar la muerte de sus hermanastros.

Arias González, padre de nuestro escritor, volvió a Castilla con los hijos, tres de los cuales los acogió bajo su tutela su tío Simón de Cisneros, obispo de la diócesis de Sigüenza. Todos ellos siguieron la vida religiosa.

Juan Ruiz o Rodríguez de Cisneros nació en el cautiverio como segundo hijo natural de Arias González, el señor de Cisneros. Cuando tenía diez años, regresó a Castilla con su padre y sus hermanos. Los años vividos en Andalucía le permitieron conocer la lengua, las 
costumbres y la cultura de los musulmanes asentados en la Península y también de los judíos, muchos de los cuales vivían allí participando en la formación de la vida científica, artística y cultural. Los ecos de todo aquello los encontraremos en su obra. El arte desarrollado por los cristianos bajo la influencia árabe se denomina mudéjar. Así pues, podemos hablar del mudejarismo del Libro de Buen Amor. El mudejarismo se manifiesta en la temática, la lengua, el conocimiento de las costumbres; asimismo embellece el mundo árabe.

Después de haber vuelto a la zona cristiana, Juan Ruiz se instaló en la casa de su tío Simón de Cisneros y se dedicó a la carrera eclesiástica. Gracias a la protección de la reina María de Molina y de Gil Albornoz, arzobispo de Toledo (1338-1367), ascendió rápidamente en la jerarquía de la Iglesia y ya con dieciséis años fue nombrado canónigo de Sigüenza, la capital eclesiástica de Guadalajara, cerca de la localidad Hita. Después ocupó cargos de responsabilidad en diversas partes de Castilla. Todo ello explica la riqueza de su lenguaje y el conocimiento de la geografía que se manifiestan en la obra. A causa de su protector, el arzobispo Albornoz, Juan Ruiz estaba particularmente vinculado con Toledo donde seguía reinando el ambiente intelectual que se originaba de los tiempos del Alfonso X. Siendo todavía un joven clérigo, obtuvo el título de capellán papal y para recibir este nombramiento tuvo que acudir en persona a la corte del papa que en aquel entonces residía en Avignon. El papa consintió que emprendiera los estudios de tres años de duración sin perder el beneficio eclesiástico.

Juan Ruiz se encontró en una situación privilegiada, dado que pudo estudiar teniendo asegurada su existencia. En los siglos XIII y XIV el nivel del clero de la Península era muy bajo, tenemos testimonios de esto en los informes de los visitadores eclesiásticos. Los clérigos no podían cursar los estudios porque el hecho de alejarse de los sitios donde tenían el beneficio eclesiástico comportaba su retención. El clero más bajo, proveniente de familias pobres, no disponía entonces de medios que le permitiera emprender los estudios. Mientras que Juan Ruiz los poseía. Aprovechó este período no sólo para profundizar sus conocimientos teológicos y generales, sino que también entró en contacto con la cultura europea y con el mundo de los 
goliardos: estudiantes, clérigos sin órdenes que vagabundeaban por las ciudades y, muy a menudo, se ganaban la vida mediante su creación artística satírica y picante, presentada en las tabernas y plazas públicas. Todos estos contactos enriquecieron su futura obra.

No sabemos exactamente qué hacía Juan Ruiz tras haber vuelto de Avignon, llegamos a saber sólo que se halló en la cárcel de Toledo donde pasó trece años y allí, según él mismo nos cuenta, escribió el Libro de Buen Amor, que fue terminado en 1343. No se conoce la fecha de su muerte. Se considera que su protector, el arzobispo Gil de Albornoz, el fundador del Colegio de España de Bolonia, lo encarceló a causa de haber escrito una sátira contra los clérigos de Talavera, famosos por su vida disoluta. Esta sátira se publica junto con su obra. La vida del clero, que en aquel entonces no era muy pudorosa, se conocía y se criticaba, pero el excepcional don humorístico de nuestro autor le permitió escribir una sátira particularmente mordaz y muy popular entre los lectores. En todo caso, su obra principal tampoco está privada de la crítica de las costumbres del clero.

El Libro de Buen Amor es una obra cuyo mensaje no es unívoco, lo cual dio ocasión a interpretaciones incluso contradictorias: fue considerado tanto un libro que indicaba cómo evitar el pecado como un libro obsceno. El autor declara la voluntad de escribir un libro moralizador, que incite al amor "bueno", es decir al amor hacia Dios. Él mismo dice que su intención no es enseñar cómo pecar, sino advertir contra el pecado. Presenta la lucha entre el cuerpo y el alma, el amor humano y el amor a Dios. Cada una de las aventuras relatadas termina con una decepción e indica la religión como consuelo. Se podría sospechar que es otra obra didáctico-moralizadora cuyo objetivo es ayudar al lector a profundizar el amor hacia el Creador y a evitar las tentaciones de la carne. Sobre todo, teniendo en cuenta que el elemento religioso bajo la forma de invocaciones, oraciones y poemas de devoción ocupa la gran parte de la obra. Pero no es esto lo que lo hizo famoso. Si hubiera escrito sólo esto, se habría convertido en uno de muchos escritores religiosos medievales. La segunda parte de la obra, completamente profana, es un poema sobre el amor mundano del que el autor le advierte al lector. Estas dos tramas no están separadas, se 
entrelazan armoniosamente y el paso de una a la otra se produce de una manera totalmente natural. Los fragmentos profanos fueron traducidos al polaco por Zofia Szleyen en 1981.

La parte profana relata las aventuras amorosas, supuestamente del autor mismo, en un tono burlesco-obsceno. Hay allí amor, sensualidad y pasión pero envueltos en la neblina de la alegoría y de las intenciones moralizadoras. De las páginas del libro emanan la alegría y el amor a la vida. Al escritor le hacen gracia los vicios humanos y los presenta sin la amargura propia a la literatura didáctica y de devoción de otros autores de aquel período.

El Libro de Buen Amor, aunque todavía arraigado en la tradición medieval, ya abre el período posterior formando nuevas posturas y abriendo camino para el futuro desarrollo de la literatura española. Es el primer libro escrito en castellano en primera persona, con rasgos de autobiografía. A pesar de que el autor se hace pasar por el protagonista de la obra, no pretende ofrecernos la auténtica autobiografía del poeta Juan Ruiz. Las cómicas historias de desengaños amorosos, narradas de una manera fragmentaria, son como una vida inventada del personaje histórico. Los casos de amor relatados en la obra siempre están acompañados por una reflexión moral, cuyo objetivo es recordar al lector que "el amor mundano" se ha de evitar. El autor, que esal mismo tiempo el protagonista, está en movimiento constante, cambia de objetivos amorosos y se traslada en el espacio: abandona las ciudades, camina por pueblos y sierras castellanas para después volver a regresar a la ciudad. Se ha elaborado incluso el itinerario del Arcipreste. Traslada sus sentimientos de una mujer a otra, su vista encuentra varios objetos pero no se detiene en éstos durante mucho tiempo, constituyen para él sólo la materia literaria. Según J.L. Alborg este movimiento constante que da viveza a la obra es el reflejo de la ansiedad cuyo origen fue la crisis religiosa del siglo XIV. G. Díaz Plaja llama la obra Comedia humana del siglo XIV.

Entre los temas y motivos tratados en la obra se pueden observar influencias del islam, que el autor conoció durante su infancia. Una de éstas es la condena del vino por razones morales y de salud. Este motivo está muy presente en la literatura árabe y hebrea. El Corán ex- 
plícitamente prohíbe beber vino, mientras que en las Santas Escrituras no hay nada al respecto. Trotaconventos (Obieżykruchta en la traducción polaca), uno de los personajes más logrados de la obra, tiene sus raíces también en la realidad árabe. Este tipo de intermediaria se puede encontrar en la traducción polaca de El collar de la paloma de Ibn Hazm (1976), escritor árabe del siglo XI proveniente de Córdoba. La alcahueta que facilita los contactos entre amantes era un personaje muy popular del islam. Este tipo de personaje no era exclusivo de la cultura árabe, ya que también se hallaba los en la literatura romana; con todo, el ambiente en el que actúa es el reflejo de la cultura con la cual el poeta había tenido contactos en su infancia. Juan Ruiz creó una silueta inolvidable de la vieja mujer trotando de puerta en puerta para ganarse la vida gracias a sus servicios no muy edificantes. No obstante, aquélla se quedará relegada a la sombra por otro personaje inmortal de alcahueta, la Celestina de la tragicomedia de Fernando de Rojas de 1499. Ésta última ganará fama fuera de España gracias a las traducciones a otras lenguas. M.R. Lida [1966] señaló la semejanza de estructura de la obra a la maqama semítica, género creado en el siglo $\mathrm{X}$ por el árabe al-Hamadhaní y practicado hasta el siglo XIV. La estructura de este género se caracteriza por el hecho de que el narrador y el protagonista se funden y se identifican con el autor y en la trama se insertan aforismos, proverbios, parodias, fábulas, retratos. Desde el punto de vista formal es una combinación de poesía lírica y prosa rimada. Algunos apólogos y fábulas, de los que el autor se sirve con mucho gusto, hacen alusión al contacto que tuvo Juan Ruiz con el mundo oriental.

Los viajes del autor por los caminos y yermos de Castilla, los encuentros que le permiten elaborar una galería de personajes, hacen de la obra la precursora de la novela picaresca del Siglo de Oro (ss. XVI y XVII), cuyo antihéroe también recorre caminos, encuentra muchos tipos humanos y experimenta varias situaciones vitales. El paso de un amor a otro anuncia la aparición del personaje literario de Don Juan. Los viajes del pícaro se originaban en aquel que no encontraba en su vida nada firme, nada en que pudiera apoyarse. La inconstancia de Don Juan también es un síntoma de la ansiedad interna. De manera 
similar era inestable el suelo en el que se apoyaba el hombre del siglo $\mathrm{XIV}$, desgarrado internamente a causa de la crisis de fe, que hasta ese momento constituía para él un soporte seguro y una guía.

El tema central de la obra es el amor, aunque difiere su presentación de la que solían hacer los autores medievales. El amor en la Edad Media rara vez era un tema literario y si ya se introducía a la literatura, era sólo a fin de condenarlo. Por supuesto, existía la poesía de los trovadores occitanos que se filtró en la Península Ibérica. Con todo, era una poesía que trataba el amor de una manera extremadamente convencional o hermética. No era un sentimiento que se experimentara con alegría y despreocupación, puesto que el amor alabado por los trovadores exigía sufrimientos y su finalidad no era la consumación corporal. El donjuanismo del Arcipreste de Hita se origina en que todo es una ilusión, un espejismo. Lo ilustra la fábula del perro que corriendo con una lonja de carne en la boca se vio reflejado en el agua y al intentar agarrar el otro pedazo, se le cayó el que ya tenía entre los dientes. La descripción del amor único, proveniente de Italia, no llegará a España antes del siglo XVI. Su elogiador será el gran poeta renacentista Garcilaso de la Vega.

Juan Ruiz es un evidente admirador de las mujeres. No son para él, ni mensajeras del infierno que tientan a los hombres, ni la encarnación del pecado. Describe con detalles una mujer "ideal". Debería ser de talla mediana, ni demasiado baja, ni demasiado alta, con caderas anchas, tener cabeza pequeña, pelo rubio, cejas apartadas y bellamente arqueadas, orejitas pequeñas, ojos grandes y sonrientes, nariz afilada, dientes pequeñitos, rectos y muy blancos, boca pequeña, tez blanca y mejillas de color rosa. En esta caracterización se nos presenta un verdadero conocedor de los encantos femeninos. A pesar de esto, algunos críticos suponen la existencia de influencias literarias en el retrato arriba trazado. Según Dámaso Alonso se ven allí influencias árabes, mientras que L. Spitzer considera que esta visión se origina en las fuentes latinas y es una descripción estereotipada de la belleza femenina. Juan Ruiz nos dejó también el retrato de él mismo: sería alto, musculoso, ancho de brazos, de labios carnosos y ojos pequeños. 
En la Edad Media la literatura era sobre todo moralizadora. Casi cada autor intentaba con su obra dar una lección y presentar un ejemplo edificador. Juan Ruiz desnuda los vicios humanos, pero lo hace con ironía, éstos no impiden sentir la alegría y el amor a la vida. Este tipo de actitud hacia la vida terrenal era excepcional en sus tiempos. Juan Ruiz se convierte, de esta manera, en el precursor del Renacimiento. Es el primer gran humorista español, le hacen gracia las debilidades de sus prójimos.

Juan Ruiz era una persona de gran cultura literaria y se servía con habilidad de los modelos de la Antigüedad, la tradición autóctona, el conocimiento de las culturas árabe y hebrea, elaborando una síntesis de todo lo que existía e indicando nuevas direcciones a sus sucesores. Su postura, moderna para aquella época, se manifiesta entre otros en su actitud hacia la obra misma. Tiene plena conciencia de que escribe un libro novedoso. No obstante, utiliza la forma tradicional: el verso. Ya en aquella época, tras los Pirineos, las novelas de los Caballeros de la Mesa Redonda tenían nuevas versiones en prosa. El tema sería adecuado para una obra en prosa, pero cuánto perdería en lo artístico sin las serranillas populares o el zéjel árabe, toda esa riqueza de la variedad de metros.

El autor es plenamente consciente de que escribe un libro novedoso. Al ser novedoso, requiere de una comprensión adecuada. Con este fin recurre al intelecto del destinatario, que lo ayudará a entender de manera adecuada la intención y el mensaje del autor. Preocupándose por la comprensión apropiada, explica qué quería decir: a pesar de que la naturaleza nos empuja hacia el pecado, hay que evitarlo. Entrega la obra a las manos del lector, dándole permiso para enmendarla y escribir la continuación. Esta actitud es completamente opuesta a lo que dijo, en el prefacio de El Conde Lucanor, un escritor contemporáneo al Arcipreste, Don Juan Manuel. Éste último explica que escribe con una lengua clara y sencilla para que cada uno lo comprenda y no aplique ninguna corrección. Ambos escritores tratan sus obras de manera moderna, preocupándose por la recepción, pero entendiéndola de un modo diferente, pues el primero entrega su obra a la nación autorizándola a enmendarla y continuarla, en este sentido podemos 
hablar de obra abierta. Esta actitud es más frecuente entre los autores españoles, los cuales, según Ramón Menéndez Pidal [1971], escriben sus obras para la nación y se las entregan. Por otro lado, el aristócrata Don Juan Manuel escribe una obra cerrada, que constituye su propiedad exclusiva, que está escrita de acuerdo con sus convicciones, no se puede corregir ni un sólo detalle ni escribir la continuación para no deformarla. Don Juan Manuel escribía para la minoría, pero también pertenece a la minoría entre los escritores españoles. La mayoría, al igual que Juan Ruiz, entregaban la obra a la nación para que le sirviera, considerando que la nación tenía derecho de corregirla y continuarla. Quizá de ahí que sean tan numerosas en la literatura española las continuaciones de obras muy populares y las paráfrasis a lo divino.

Recurriendo a distintos modelos, Juan Ruiz cita o parafrasea las obras de los escritores de la Antigüedad más conocidos en aquel entonces, como La Política de Aristóteles, el Ars amandi de Ovidio y las fábulas de Fedro. Se puede ver en su obra el conocimiento del teatro escolar medieval, escrito en latín. Aparte de las fábulas orientales, se sirve de los fabliaux franceses, hace uso de temas alegóricos muy extendidos en Europa como, por ejemplo, el Combate entre la Cuaresma y el Carnaval.

El autor está orgulloso de que ha escrito su obra con un verso tan bello. La polimetría de la obra es uno de sus valores principales. Predomina la cuaderna vía: la estrofa de cuatro versos de catorce sílabas con rima consonante uniforme, propia de la poesía "docta" denominada mester de clerecía ejercida por los clérigos, destinada al público culto y cuya recepción se producía mediante la lectura. Con esta estrofa fue escrito el poema sobre Alejandro Magno y a partir de aquel entonces el verso de catorce sílabas en la poética española se denomina alejandrino. Esta poesía se oponía al mester de juglaría, poesía popular, transmitida oralmente, que no contaba escrupulosamente las sílabas y se servía de la rima asonante, además de ser despreciada por los clérigos. El Arcipreste rompe con gusto la monotonía y al lado de la estrofa cuaderna vía, que en su caso es muy bella, maneja una variedad de metros. La polimetría es, según Menéndez Pidal [1971], 
una de las características de la poesía medieval española. Como ejemplo, el gran medievalista español cita la traducción anónima del $R o-$ man de Troie (hacia 1270) del autor francés Benoît de Sainte-Maure. La obra escrita exclusivamente con dísticos octosílabos fue traducida sirviéndose de seis diferentes tipos de estrofa.

Entre las estrofas que aparecen en el Libro de Buen Amor la más interesante es la mencionada serranilla octosílaba. Es de procedencia popular y por primera vez aparece en la literatura bajo la pluma del Arcipreste de Hita. En cuanto a la temática, pertenece al mismo género que la pastourelle, el rondel y la ballade franceses: es una canción sobre serranas o campesinas con las cuales se encuentra un caballero y cuya hermosura despierta la admiración del joven. El tema está presente también en la literatura francesa, sobre todo en la pastourelle, con la diferencia de que la doncella española siempre sabe rechazar el cortejo inadecuado. Una de las mencionadas cancioncillas es una sátira o parodia evidente de la mujer alabada por los trovadores. La serrana con la que se cruza el autor es horrorosamente fea, gigantesca y acecha a los hombres que atraviesan el desfiladero para violarlos. Asimismo, se puede entender la aparición de este personaje como una alegoría del deseo, normalmente representada como un salvaje.

Juan Ruiz utiliza también el zéjel, una estrofa de procedencia árabe que constaba de tres elementos. Comienza con el estribillo que impone el tema, al que sigue el desarrollo del tema y al final se repiten los versos del estribillo. De esta estrofa se origina el villancico popular, muy frecuente en la poesía lírica. Juan Ruiz utiliza por primera vez el endecasílabo, muy raro en la poesía medieval española que se propagará bajo la influencia italiana en el Renacimiento. Muy bellas son algunas canciones a la Virgen, escritas en octosílabos: el metro de la poesía popular; es una muestra de la auténtica devoción del autor. La variedad de metros, característica para la creación literaria española, era una de las ventajas y encantos del teatro del Siglo de Oro.

La parte profana de la obra en gran parte tiene forma de diálogo que es por excelencia un medio de expresión dramática. No es de extrañar que se represente como función. Tuve la oportunidad de ver un espectáculo de este tipo en Hita con ocasión del Congreso Interna- 
cional dedicado a los inicios del teatro español. No se puede excluir que la obra soliera representarse también en la Edad Media en los teatros escolares.

Desde las páginas del libro se nos presentan auténticas escenas de la vida cotidiana de la España medieval. De vez en cuando se critica a las mujeres, sin malicia, con una sonrisa indulgente. La obra tampoco carece de la crítica del clero: su falta de formación, el excesivo interés por las cuestiones económicas y por las mujeres. Sería conveniente recordar que es el papa Calixto II quien, durante el Concilio de Letrán en 1123, proclamó la prohibición categórica de contraer matrimonios por los sacerdotes. Hasta la instauración del celibato, la mayor parte del clero contraía matrimonios; después de haberlo establecido los sacerdotes durante mucho tiempo siguieron viviendo en concubinato, sin poder someterse al cambio introducido. De ahí muchas sátiras contra los sacerdotes que no cumplían con el celibato. Los ecos de todo aquello son visibles también en la obra del Arcipreste. No obstante, no se puede considerar la obra de anticlerical tal y como les hubiera gustado a algunos críticos. El hecho de reflejar las costumbres, la capacidad de captar la realidad le dan a la obra un carácter de documento sobre la sociedad. A través de ella conocemos las costumbres de ciudades y pueblos, sabemos cómo se vestían las mujeres y qué se comía, cuáles eran las costumbres de los árabes y judíos que vivían en la Península, y muchas cosas más.

Juan Ruiz no dio título a su libro. Dentro de la obra misma la llamó algunas veces "libro de buen amor" y así la tituló Menéndez Pidal. Al principio se conocía también bajo el título Libro de cantares. Solamente en este título podemos encontrar ecos del lirismo tan presente en la obra. Particularmente líricas son algunas canciones dedicadas a la Dolorosa, el reflejo de la simple religiosidad popular, a Cristo Mártir y muchas más de temática profana.

El Libro de Buen Amor es una obra maestra a caballo entre la Edad Media y el Renacimiento, el hálito de este último ya se puede percibir claramente en la obra. No se ha conservado el autógrafo, sólo algunas copias posteriores, pero en España no es un caso aislado. Muchos manuscritos se perdieron durante guerras, incendios, saqueos de 
iglesias y monasterios durante los levantamientos sociales dirigidos contra la Iglesia. No se han catalogado por completo las bibliotecas de iglesias, monasterios y ni siquiera universidades. Pueden seguir ocultando muchos manuscritos desconocidos.

El hecho que determina si una obra es una obra maestra es el inagotable interés por ésta, su atemporalidad. El Libro de Buen Amor resulta no sólo una obra leída por el lector español, sino también un objeto de interés de la crítica. Si se trata del libro del Arcipreste de Hita, hasta ahora le han sido dedicados más de cuatrocientos trabajos que varían en dimensiones y valor. Los críticos se ocupan de manuscritos, la versificación, la lengua, las influencias, la alegoría, la crítica social que presenta, el didacticismo, la astrología, el tema de la muerte tratado en la obra y muchos aspectos más.

El Libro de Buen Amor es de carácter antológico: presenta diversos tipos de versificación y temática, múltiples influencias literarias, reflexiones morales, un estilo heterogéneo, una variedad de géneros literarios practicados en la Edad Media. Hay que subrayar que todos estos géneros se actualizan en la obra, lo cual es un indudable mérito del autor. Nos podemos atrever a llamar esta obra la síntesis de elementos de la literatura medieval española. Vale la pena reflexionar si la elaboración de una síntesis como ésta no fue, de hecho, la intención consciente del autor. Habría podido hacerlo no sólo para mostrar la maestría poética y su cultura literaria, sino también para reflejar de esta manera el caos en el que vivía el hombre de aquella época. No obstante, no es un caos total, dado que la unidad la garantiza el protagonista, narrador y comentador, es decir, el autor. El protagonista busca aventuras amorosas, el narrador se sirve de sus experiencias para elegir entre el bien y el mal, al final el comentador interrumpe el relato para pronunciar sermones en un tono medio serio medio burlón o incluso parodia los sermones que tratan del peligro que trae consigo el amor pecaminoso y finalmente el poeta deslumbra con su maestría.

¿Cuál es entonces el mensaje del autor? ¿Quiere incitar o de veras advertir contra el amor? Toda la obra está llena de contradicciones que se producen en muchos niveles. Por un lado tenemos dogmas, deberes sacerdotales, el deseo de realizar obras de misericordia y, por otro 
lado, las propensiones biológicas y las necesidades naturales. Hay un juego constante entre el amor loco y el bueno, dos amores que entran en contradicción: el dilema entre la salvación y el pecado. Era un dilema adecuado para la retórica basada en contradicciones y gozaba de popularidad en los debates medievales. Según esta retórica cada cosa origina la contradicción y depende de ella, es decir, el amor a Dios se transforma en el amor carnal y se convierte de esta manera en un amor bueno. La contradicción entre la castidad y la naturaleza humana formaba parte de la realidad histórica de la época de Juan Ruiz. En la misma construcción de la obra también hay contradicciones entre el arte juglar, recitado en las plazas públicas, acompañado por gestos, cantos, chistes, saltos y bailes, y el arte culto que se manifiesta mediante glosas, ejemplos, alegorías, el lado moralista. Siempre hay dos aspectos conflictivos que reflejan la realidad conflictiva en la que vivió el autor. En esta situación conflictiva se encuentra el mismo Arcipreste. Es lo que explica la ambigüedad del mensaje comprendido en la obra. Otra obra igualmente ambigua se escribirá cien años más tarde por el Arcipreste de Talavera, Alfonso Martínez.

\section{Biblografía}

GARIANO, C. (1967), El Mundo poético de Juan Ruiz, Gredos, Madrid.

GUZMÁN, J. (1963), Una constante didáctico-moral del «Libro de Buen Amor», Cultura, México.

LIDA, M.R. (1966), Dos obras maestras españolas: «El libro de Buen Amor» $y$ "La Celestina», Editorial Universitaria, Buenos Aires.

LÓPEZ ESTRADA, F. (1979), Introducción a la literatura medieval española, Gredos, Madrid.

MACRI, O. (1969), Ensayo de métrica sintagmática. (Ejemplos del «Libro de Buen Amor» y del «Laberinto» de Juan de Mena), Gredos, Madrid.

MENÉNDEZ PIDAL, R. (1971), Los españoles en la literatura, Espasa Calpe, Madrid.

RÍO, A. del (1970), Historia literatury hiszpańskiej, t. I, Państwowe Wydawnictwo Naukowe, Warszawa. 
Juan Ruiz, Arcipreste de Hita: Libro de Buen Amor...

RUIZ, J., ARCIPRESTE DE HITA (1972), Libro de Buen Amor, Salvador Miguel, N. (ed.), Magisterio Español, Madrid.

RUIZ, J., ARCIPRESTE DE HITA (1980), Księga Dobrej Miłości, trad. Z. Szleyen, Państwowy Instytut Wydawniczy, Warszawa. 